\title{
Isoform of APOE with retained intron 3; quantitation and identification of an associated single nucleotide polymorphism
}

\author{
Laura S Dieter, Steven Estus ${ }^{*}$
}

\begin{abstract}
Background: Alleles of apolipoprotein E (APOE) are the major genetic risk factor for late onset Alzheimer's Disease (LOAD). Recently, an APOE splice variant that retains intron 3 (APOE-13) was identified. To gain insight into the possible role of this isoform in LOAD, we quantified its expression in a cohort of 56 human brain specimens by using quantitative RT-PCR.

Results: We found that APOE-13 generally represents a low percentage $(<0.5 \%)$ of overall APOE expression. However, in one specimen, the proportion of APOE-13 was increased about $\sim 13$ fold. This specimen was unique in the cohort for possessing the minor allele of an intron 3 single nucleotide polymorphism (SNP), rs12982192. Additionally, an allelic expression imbalance study indicated that the rs12982192 minor allele was associated with increased APOE-13 expression.

Conclusions: Overall, we interpret our results as suggesting that APOE-13 represents a minor portion of APOE expression and that rs 12982192 is associated with APOE intron 3 retention. Since the minor allele of this SNP is on the same haplotype as the minor allele of rs429358, which defines the APOE4 allele, we speculate that rs12982192 may reflect a modest loss of mRNA encoding functional APOE4.
\end{abstract}

\section{Background}

$A P O E$ variants are the single largest genetic factors impacting late onset Alzheimer Disease (LOAD), the most common neurodegenerative disease. In particular, the $A P O E 4$ allele confers increased risk, being present at a $\sim 15 \%$ frequency in the general population and at $50 \%$ in LOAD [1,2]. APOE consists of 4 exons and 3 introns encoding a total of 317 amino acids. After cleavage of the signal peptide, the mature APOE protein is 299 amino acids. Protein translation begins in exon 2 and ends in exon 4. In the brain, APOE transports cholesterol and modulates Aß clearance [1,2]. APOE is primarily secreted by astrocytes [3,4] with microglia [5] and, possibly, stressed neurons also contributing to APOE production [6]. Overall, insights into $A P O E$ expression will provide further information on $\mathrm{AD}$ risk.

Recently, Xu et al reported an $A P O E$ isoform that retained intron 3 (APOE-I3) and was increased with

\footnotetext{
* Correspondence: steve.estus@uky.edu

Department of Physiology and Sanders-Brown Center on Aging, University of Kentucky, Lexington, KY, USA
}

neuronal stress in murine models [7]. To gain insights into this novel $A P O E$ isoform in humans, we quantified $A P O E-13$ as well as the normal length APOE (APOE-NL) in a cohort of $56 \mathrm{AD}$ and non-AD brain samples. We report that $A P O E-I 3$ represents a low proportion of overall $A P O E$ expression. In addition, we identified an individual with significantly increased expression of the $A P O E$ $I 3$ isoform. Further analysis revealed that this individual was unique in the cohort for an intron 3 single nucleotide polymorphism (SNP), rs12982192. Moreover, APOE-I3 was in allelic expression imbalance (AEI) in this individual such that the minor allele of rs12982192 correlated with increased expression of the APOE-I3 isoform. Overall, we interpret our results as suggesting that $A P O E-I 3$ represents a minor portion of $A P O E$ expression and that rs12982192 is associated with $A P O E$ intron 3 retention.

\section{Materials and methods Human autopsy tissue}

The human autopsy tissue specimens used here have been described elsewhere [8,9]. Briefly, anterior cingulate tissue 
was provided by the University of Kentucky AD Center. Diagnoses of $\mathrm{AD}$ and non-AD were based upon evaluation of both cognitive status, i.e., Clinical Dementia Rating and Mini-Mental State Examination scores, as well as neuropathology [10]. The age at death for individuals that were cognitively intact, i.e., non-AD, was $82 \pm 9$ years (mean \pm $\mathrm{SD}, \mathrm{n}=29$ ) while age at death for AD individuals was $82 \pm 6(\mathrm{n}=27)$. The average post-mortem interval for non- $\mathrm{AD}$ and AD individuals was $2.8 \pm 0.8$ hours (mean \pm $\mathrm{SD}, \mathrm{n}=29)$ and $3.4 \pm 0.6$ hours $(\mathrm{n}=27)$, respectively. The non-AD and AD individuals were well-balanced for sex, i.e., 15 of the 29 non-AD individuals were women while 14 of the $27 \mathrm{AD}$ individuals were women.

\section{PCR amplification}

RNA was extracted and converted to cDNA as described previously $[8,9]$. To initially visualize the $A P O E$ isoforms (Figure 1A), APOE-I3 was amplified with primers that corresponded to sequences within exon 2 (primer E2: CGTTGCTGGTCACATTCCT) and intron 3 (I3: AGAGAGAGACAAAGCTGAGA). The normal length $A P O E$ isoform $(A P O E-N L)$ was amplified with the same exon 2 primer and a reverse primer that corresponded to the exon 3-4 junction (E3-4 Junc: CCATCAGCGCCCTCAGTT) (Figure 1A). The equivalent of $20 \mathrm{ng}$ of template cDNA was amplified with $1 \mu \mathrm{M}$ of each primer in a PCR profile consisting of pre-incubation for 3 minutes at $94^{\circ} \mathrm{C}$, followed by cycles of $94^{\circ} \mathrm{C}$ for $30 \mathrm{sec}, 60^{\circ} \mathrm{C}$ for $30 \mathrm{sec}$ and $72^{\circ} \mathrm{C}$ for $30 \mathrm{sec}$ (Perkin Elmer 9600). PCR products were separated by polyacrylamide gel electrophoresis and visualized by SYBR-gold staining and fluorescence imaging (FujiFLA-2000). The PCR products were isolated from the gel and identified by direct sequencing (Davis Sequencing). For real-time quantitative PCR (RT-qPCR), reaction mixtures consisting of $1 \mathrm{uM}$ each primer, $1 \times$ SYBR-green Master Mix (Applied Biosystems) and $20 \mathrm{ng}$ of template cDNA were pre- incubated for 10 minutes at $95^{\circ} \mathrm{C}$ followed by 40 cycles of $94^{\circ} \mathrm{C}$ for $30 \mathrm{sec}, 60^{\circ} \mathrm{C}$ for $30 \mathrm{sec}$ and $72^{\circ} \mathrm{C}$ for $30 \mathrm{sec}$ (BioRad Chromo4). After completion of the RT-qPCR cycles, assay specificity was confirmed by melting curve analysis and by visualizing the products by polyacrylamide gel electrophoresis and SYBR-gold staining. Copy numbers were determined relative to standard curves that were amplified in parallel; the standards were generated from PCR-amplified products that were gel purified and quantified by UV absorbance. Each sample was analyzed twice by RT-qPCR. The limit of detection was five copies of $A P O E$ isoform per $20 \mathrm{ng}$ of cDNA. Copy numbers were normalized to the geometric mean of the copy numbers of hypoxanthine-guanine phosphoribosyltransferase 1 and ribosomal protein L32 [11,12]. Samples were genotyped for rs12982192 by using a TaqMan approach (Applied Biosystems).

\section{Allelic expression imbalance}

To determine whether each allele of rs12982192 and rs429358 contributed equally to $A P O E-I 3$ and $A P O E-$ $N L$, respectively, we cloned the $A P O E-I 3$ and $A P O E-N L$ PCR products from specimen \#31 (TA-Cloning pcDNA3.1, Invitrogen). The identity of each clone was confirmed by direct sequencing (Davis Sequencing). We then estimated the proportion of each allele present in specimen \#31 APOE-I3 and APOE-NL cDNA by comparing the relative sequencing electropherogram peak areas of each allele of rs12982192 and rs429358, respectively, essentially as described [13]; the results of this assay were normalized relative to standard curves derived from varying proportions of each allelic clone and validated by analysis of genomic DNA (gDNA).

\section{Statistical Analysis}

The association between $A P O E-I 3$ and/or $A P O E-N L$ and sex, age, PMI and $A P O E 4$ genotype was analyzed by

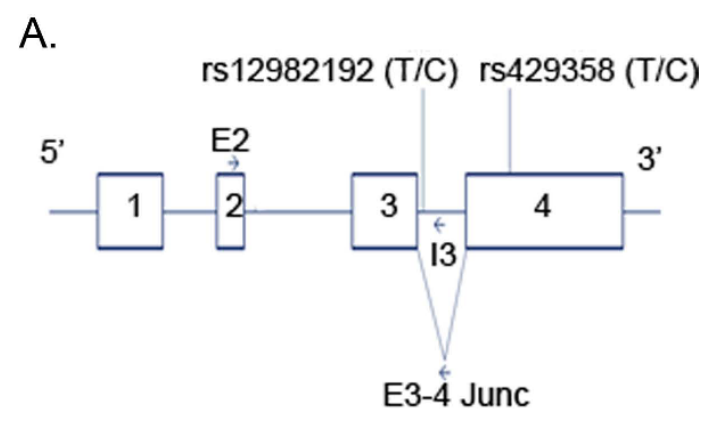

B.

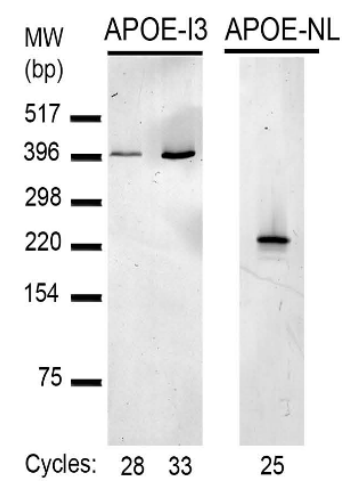

Figure 1 PCR Detection of APOE-NL and APOE-I3. PCR primer positions are depicted relative to the four exons of APOE (A). TwO SNPS are also shown: rs12982192 within intron 3 and rs429358, which determines APOE4 status, in exon 4. PCR of 25 or $28-33$ cycles was used to detect APOE-NL and APOE-13, respectively, in pooled brain CDNA samples (B). 
linear regression (SPSS v 17.0). Differences in AEI in gDNA and cDNA were evaluated by a two-tailed T-test (SPSS, V17). A p $<0.05$ was considered to be significant.

\section{Results}

To begin to evaluate $A P O E-I 3$ and $A P O E-N L$ expression, we amplified human brain cDNA by using a forward primer within exon 2 (E2) and reverse primers within intron 3 (I3) or the junction of exon 3-4 (E3-4 Junc), respectively (Figure $1 \mathrm{~A}$ ). Both the $A P O E-I 3$ and the $A P O E-N L$ isoform were readily discernible (Figure $1 \mathrm{~B}$ ). We then used RT-qPCR to quantify each $A P O E$ isoform in $20 \mathrm{ng}$ of cDNA prepared from 56 human brain samples and the results normalized for housekeeping gene expression. We found that $A P O E-I 3$ expression was low relative to $A P O E-N L$ expression (Figure 2). Indeed, the $A P O E-I 3$ isoform was not detected in 43 of the 56 specimens and was very low in another 12 of the samples, averaging $0.22 \%$ of $A P O E$ message. Interestingly, the cDNA from the remaining sample (specimen \#31) had much higher $A P O E-I 3$, reaching $2.8 \%$ of total $A P O E$ expression (Figure 2). This autopsy brain specimen was from a 91 year old, cognitively-intact person with a Braak stage of II and an $A P O E 3 / 4$ genotype. Excluding this outlier and samples where APOE-I3 was not detected, there was a strong trend between the expression of $A P O E-N L$ and APOE-I3 ( $\mathrm{p}=0.053)$. The

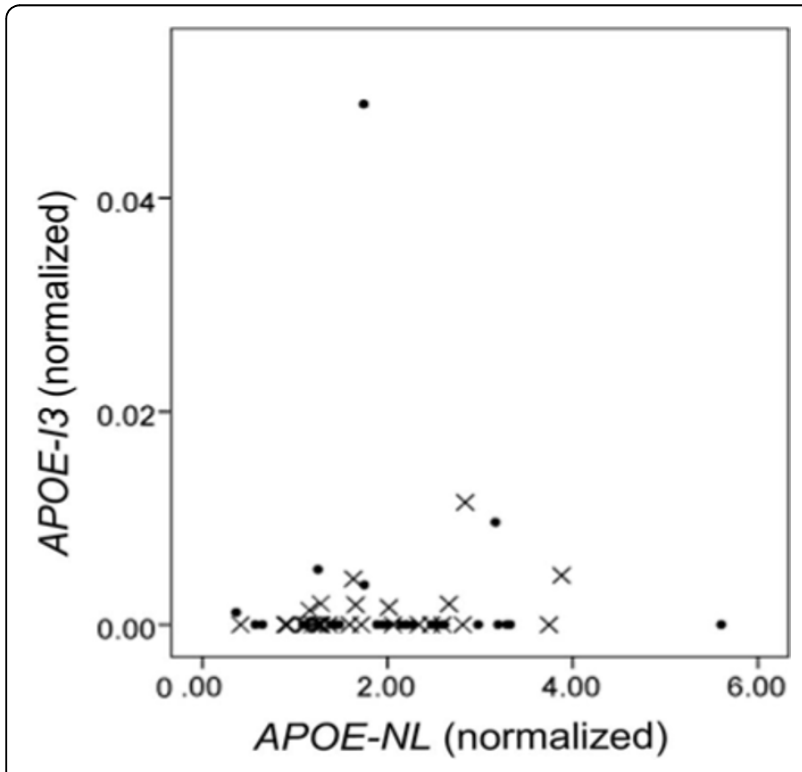

Figure 2 Quantification of $A P O E-I 3$ and $A P O E-N L$ Expression. Expression of $A P O E-13$ is shown as a function of $A P O E-N L$ in $A D(X$ markers) and non-AD (circle markers) samples. Specimen \#31 is the non-AD outlier with a high level of APOE-13 expression. RT-qPCR data were normalized to the geometric mean of hypoxanthineguanine phosphoribosyltransferase and ribosomal protein L32. There was no correlation of APOE-13 or APOE-NL with APOE3 versus APOE4 genotype, or AD status (data not shown). expression of neither isoform correlated with $\mathrm{AD}$ diagnosis, PMI, gender, $A P O E$ genotype or age (p > 0.05). Hence, $A P O E-I 3$ is a relatively rare $A P O E$ isoform in this cohort, with one specimen showing $\sim 13$-fold higher APOE-I3 levels.

To identify SNPs that may underlie the increased $A P O E-I 3$ in specimen \#31, we generated genomic APOE clones from exon 2 to exon 4 of this individual. These clones included the intervening 1,092 bp intron 2 and $580 \mathrm{bp}$ intron 3. Sequencing revealed that this gDNA was heterozygous for (i) rs12982192, which is a rare T/C SNP located 50 bp into intron 3 (dbSNP Build 131), (ii) rs769449, which has a $6.5 \%$ minor allele frequency and is located 78 bp into intron 2, (iii) rs769450, which has a $39.9 \%$ minor allele frequency and is also located within intron 2, and (iv) rs429358, which is within exon 4 and determines $A P O E 3 / 4$ status (Figure 1A). The APOE4 haplotype (rs429358C) contained the minor rs12982192C and rs769449A alleles and the major rs769450G allele. Since rs12982192 is within the retained intron 3 , we hypothesized that the minor rs $12982192 \mathrm{C}$ allele may be associated with APOE-I3. To test this possibility, we first assessed whether the minor allele of rs12982192 was present in any of the other 55 DNA samples in this study; only specimen \#31 possessed the minor rs12982192C allele. This finding supports the possibility that intron 3 retention is associated with rs12982192.

To evaluate this possibility further, we reasoned that APOE-I3 should be in allelic expression imbalance (AEI) with respect to rs12982192 genotype, that is, we hypothesized that the minor rs12982192C allele would be over-represented in $A P O E-I 3$. Hence, we compared the proportion of each rs12982192 allele in APOE-I3. In addition, to evaluate whether the bulk of $A P O E$ expression, as reflected by $A P O E-N L$, was in AEI in specimen $\# 31$, we also analyzed $A P O E-N L$ by using rs429358 in exon 4. Standard curves demonstrated the linearity of the AEI assay (Figure 3). The assay was further validated by testing gDNA, which found that, as expected, each allele was present in equal proportions for both rs12982192 and rs429358 (Figure 4A-B). As previously reported for $A P O E$ expression generally [14], $A P O E-N L$ expression in specimen \#31 did not show evidence of AEI (Figure 4B). In contrast, APOE-I3 showed robust AEI in specimen \#31, with significant over-representation of the minor rs12982192C allele (Figure 4A). Hence, these results support the hypothesis that the minor rs12982192C allele is associated with increased APOE-I3.

\section{Discussion}

The major findings of this paper are (i) APOE-I3 appears to be a rare $A P O E$ isoform compared to 

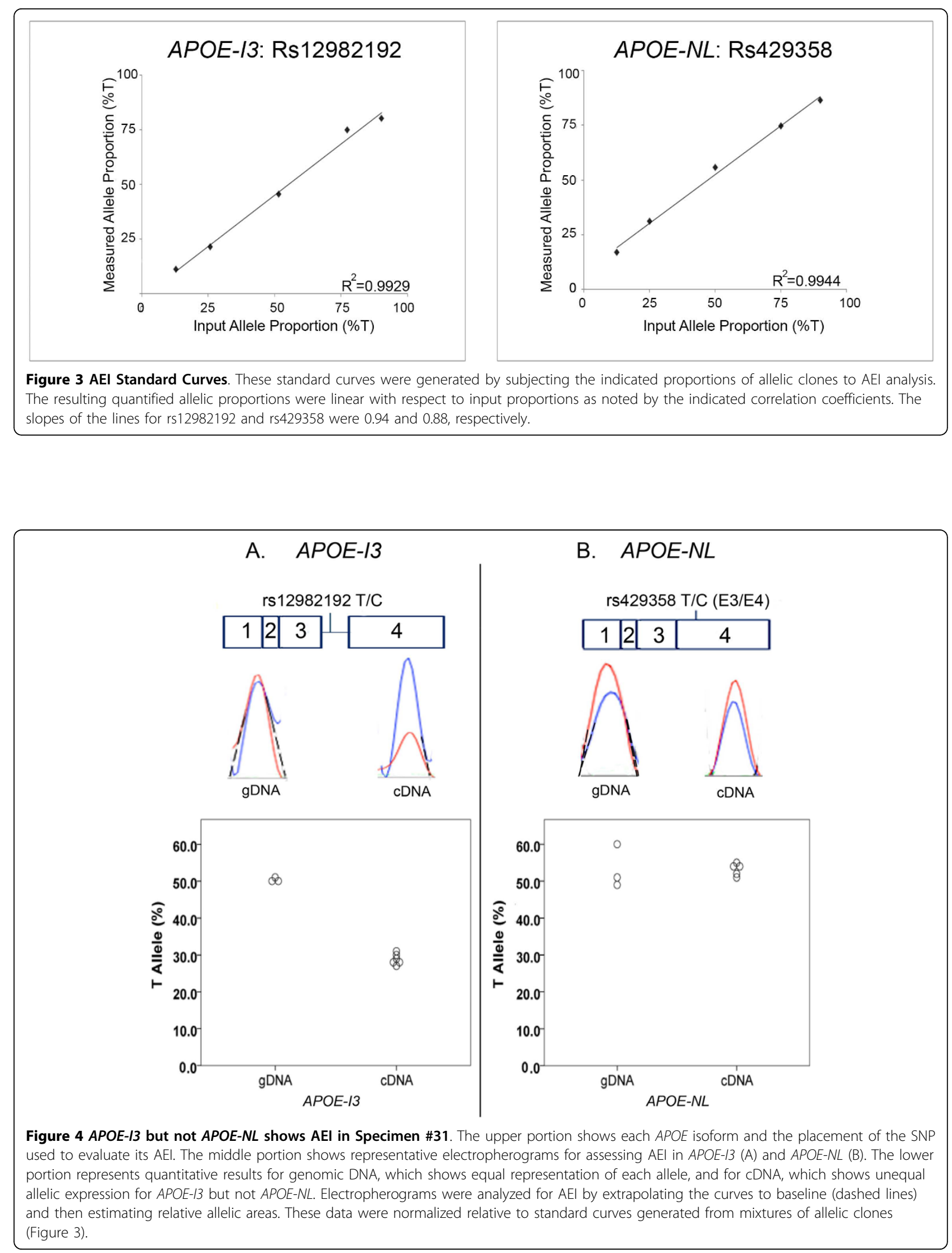
$A P O E-N L$ in the aged human brain, (ii) $A P O E-I 3$ was increased $~ 13$-fold in one individual, (iii) rs12982192, an intron $3 \mathrm{SNP}$, was uniquely present in the specimen with high $A P O E-I 3$, and (iv) APOE-I3 expression showed significant AEI in this sample, with the minor rs12982192 allele contributing a greater proportion of APOE-I3 expression. Hence, rs12982192 appears to be associated with increased expression of a rare $A P O E$ isoform.

Although the role of apoE-I3 in the brain is unclear, this isoform is infrequent relative to $A P O E-N L$. While $A P O E$ is expressed largely in astrocytes $[3,4,15]$, Xu et al found that $A P O E-I 3$ expression was restricted to neurons in mice [7]. We did not discern a correlation between the expression of $A P O E-I 3$ and synaptophysin, an mRNA restricted to neurons, although this correlation may have been precluded by the generally low APOE-I3 expression such that only 13 of the 56 samples with detectable $A P O E-I 3$ contributed to this analysis. While APOE-NL encodes a 317 amino acid secreted protein, the sequence at the exon 3 - intron 3 junction results in a stop codon. Hence, APOE-I3 encodes a truncated 79 amino acid, amino-terminal APOE fragment that is apparently not detectable in transfected cells or brain [7]. Although we considered that $A P O E-I 3$ may be a candidate for nonsense-mediated decay, $A P O E-I 3$ levels were independent of PMI (data not shown), suggesting that $A P O E-I 3$ is not rapidly degraded. In summary, the role of $A P O E-I 3$ in the brain is unclear but, given that this isoform is rare and that its encoded protein is not detectable, we speculate that APOE-I3 represents a loss of APOE mRNA encoding functional protein.

Several lines of evidence suggest that rs12982192 modulates the proportion of $A P O E-I 3$, including (i) rs12982192 resides within intron 3 consistent with its possible role as a cis-acting SNP, (ii) this SNP was uniquely present in the specimen with relatively high APOE-I3 among the 56 brain specimens analyzed, (iii) rs12982192 was associated with significant AEI for APOE-I3 with the rare rs $12982192 \mathrm{C}$ minor allele contributing a greater proportion of $A P O E-I 3$ expression and (iv) the $A P O E-N L$ isoform did not display AEI similar to the $A P O E-I 3$ isoform, ruling out the possibility of an overall APOE AEI in specimen \#31 due to other mechanisms, e.g., a promoter SNP. While this reasoning appears robust to support a role for rs12982192 in APOE-I3 splicing, two lines of evidence suggest that rs129382192 does not act independently to modulate intron 3 splicing. First, rs129382192 did not alter APOE splicing in a transfected cell, minigene paradigm (Dieter and Estus, unpublished observations), suggesting in vivo elements may be necessary to discern the actions of the SNP. Second, while the main finding of the AEI study was that the minor allele of rs12982192 was associated with increased $A P O E-I 3$ expression, a secondary finding was that the $\sim 3.5: 1$ allelic ratio was quantitatively insufficient to account for the $\sim 13$-fold increase in overall APOE-I3 expression in specimen \#31. We interpret this result as possibly reflecting additional variables specific to specimen \#31 that influence APOE-I3 or, more likely, that the difference is attributable to currently unclear technical differences between the RT-qPCR and AEI assays. In summary, although APOE-I3 levels may be modulated by additional variables, several lines of evidence support the association of rs12982192 with APOE-I3 expression.

Since $A P O E 4$ is the primary genetic risk factor for AD, SNPs that alter APOE4 expression are likely to modulate the association of $A P O E 4$ with $\mathrm{AD}$. In this regard, we note that the minor rs $12982192 \mathrm{C}$ allele is on the same haplotype as the minor rs $429358 \mathrm{C}$ allele, which defines the $A P O E 4$ allele. Since our AEI study indicates that rs12982192 is associated in cis with retention of $A P O E$ intron 3, rs12982192 may emerge as a modulator of $A P O E 4$ allelic association with AD. Hence, although APOE-I3 represents only $\sim 3 \%$ of total APOE mRNA in the rs12982192 heterozygous individual, the AEI study indicates that the majority of this $A P O E-I 3$ is derived from the $A P O E 4$ allele, and therefore could approach 5$6 \%$ of $A P O E 4$ expression. The extent that rs12982192 may be associated with $A D$ risk will require a very large study population, given the rarity of this SNP, i.e., this SNP is listed within dbSNP Build 131 without a true frequency. We note that we have genotyped an additional $\sim 800$ DNA samples and have not identified another rs12982192 carrier.

In summary, our major findings are that $A P O E-I 3$ is a low abundance $A P O E$ isoform. Moreover, the minor $C$ allele of rs12982192 appears associated with increased APOE-I3. Since the minor rs $12982192 \mathrm{C}$ allele is on the same haplotype as $A P O E 4$, and since $A P O E-I 3$ appears to represent a loss of functional APOE4 mRNA, rs12982192 may modulate the association of APOE4 with $\mathrm{AD}$ risk. Future large case-control association studies are necessary to evaluate this possibility.

\section{Abbreviations}

(APOE): apolipoprotein E; (LOAD): late onset Alzheimer's Disease; (APOE-/3): $A P O E$ splice variant retaining intron 3; (SNP): single nucleotide polymorphism; (APOE-NL): normal length APOE; (AEI): allelic expression imbalance; (RT-qPCR): real-time quantitative PCR; (gDNA): genomic DNA.

\section{Acknowledgements}

The authors gratefully acknowledge tissue supplied by the University of Kentucky AD Center, which is supported by P30AG028383, as well as NIH for grant support (R01AG026147 and P01AG030128).

\section{Authors' contributions}

LSD performed the experiments under the supervision of SE. Both authors contributed to data analysis and writing the manuscript. Both authors read and approved the final manuscript. 


\section{Competing interests}

The authors declare that they have no competing interests.

Received: 23 July 2010 Accepted: 7 September 2010

Published: 7 September 2010

\section{References}

1. Bu G: Apolipoprotein E and its receptors in Alzheimer's Disease: Pathways, pathogenesis and therapy. Nat Rev Neurosci 2009, 10:333-44.

2. Kim J, Basak JM, Holtzman DM: The role of Apolipoprotein E in Alzheimer's Disease. Neuron 2009, 63:287-303.

3. Boyles JK, Pitas RE, Wilson E, Mahley RW, Taylor JM: Apolipoprotein E associated with astrocytic glia of the central nervous system and with nonmyelinating glia of the peripheral nervous system. J Clin Invest 1985, 76:1501-13.

4. Pitas RE, Boyles JK, Lee SH, Foss D, Mahley RW: Astrocytes synthesize apolipoprotein E and metabolize apolipoprotein E-containing lipoproteins. Biochim Biophys Acta 1987, 917:148-61.

5. Stone DJ, Rozovsky I, Morgan TE, Anderson CP, Hajian H, Finch CE: Astrocytes and microglia respond to estrogen with increased apoE mRNA in vivo and in vitro. Exp Neurol 1997, 143:313-8.

6. Xu Q, Bernardo A, Walker D, Kanegawa T, Mahley RW, Huang Y: Profile and regulation of apolipoprotein $\mathrm{E}(\mathrm{apoE})$ expression in the CNS in mice with targeting of green fluorescent protein gene to the apoE locus. $J$ Neurosci 2006, 26:4985-94.

7. Xu Q, Walker D, Bernardo A, Brodbeck J, Balestra ME, Huang Y: Intron-3 retention/splicing controls neuronal expression of apolipoprotein $E$ in the CNS. J Neurosci 2008, 28:1452-9.

8. Zou F, Gopalraj RK, Lok J, Zhu H, Ling IF, Simpson JF, Tucker HM, Kelly JF, Younkin SG, Dickson DW, Petersen RC, Graff-Radford NR, Bennett DA,

Crook JE, Estus S: Sex-dependent association of a common low-density lipoprotein receptor polymorphism with RNA splicing efficiency in the brain and Alzheimer's Disease. Hum Mol Genet 2008, 17:929-35.

9. Grear KE, Ling IF, Simpson JF, Furman JL, Simmons CR, Peterson SL, Schmitt FA, Markesbery WR, Liu Q, Crook JE, Younkin SG, Bu G, Estus S: Expression of SORL1 and a novel SORL1 splice variant in normal and Alzheimers Disease brain. Mol Neurodegener 2009, 4:46.

10. Nelson PT, Braak H, Markesbery WR: Neuropathology and cognitive impairment in Alzheimer Disease: A complex but coherent relationship. J Neuropathol Exp Neurol 2009, 68:1-14.

11. Vandesompele J, De Preter K, Pattyn F, Poppe B, Van Roy N, De Paepe A, Speleman F: Accurate normalization of real-time quantitative RT-PCR data by geometric averaging of multiple internal control genes. Genome Biol 2002, 3:RESEARCH0034.

12. Zhang $X$, Ding L, Sandford AJ: Selection of reference genes for gene expression studies in human neutrophils by real-time PCR. BMC Mol Biol 2005, 6:4.

13. Heap GA, Yang JH, Downes K, Healy BC, Hunt KA, Bockett N, Franke L, Dubois PC, Mein CA, Dobson RJ, Albert TJ, Rodesch MJ, Clayton DG, Todd JA, van Heel DA, Plagnol V: Genome-wide analysis of allelic expression imbalance in human primary cells by high-throughput transcriptome resequencing. Hum Mol Genet 19:122-34.

14. Growdon WB, Cheung BS, Hyman BT, Rebeck GW: Lack of allelic imbalance in APOE epsilon3/4 brain mRNA expression in Alzheimer's Disease. Neurosci Lett 1999, 272:83-6.

15. Grehan S, Tse E, Taylor JM: Two distal downstream enhancers direct expression of the human apolipoprotein $\mathrm{E}$ gene to astrocytes in the brain. J Neurosci 2001, 21:812-22.

doi:10.1186/1750-1326-5-34

Cite this article as: Dieter and Estus: Isoform of APOE with retained intron 3; quantitation and identification of an associated single nucleotide polymorphism. Molecular Neurodegeneration 2010 5:34.

\section{Submit your next manuscript to BioMed Central and take full advantage of:}

- Convenient online submission

- Thorough peer review

- No space constraints or color figure charges

- Immediate publication on acceptance

- Inclusion in PubMed, CAS, Scopus and Google Scholar

- Research which is freely available for redistribution

Submit your manuscript at www.biomedcentral com/submit
Biomed Central 